\title{
Gonadal development and gonadotrophin secretion in the male vole (Microtus agrestis) after an abrupt change in photoperiod
}

\author{
R. P. Craven* and J. R. Clarke \\ Department of Agricultural Science, University of Oxford, Parks Road, Oxford OXI 3PF, and \\ * Department of Biology, Oxford Polytechnic, Headington, Oxford OX3 OBP, U.K.
}

\begin{abstract}
Summary. Male voles were reared from birth to age 28 days in 6L:18D. Pairs of animals showing similar sexual development were assigned at random to $16 \mathrm{~L}: 8 \mathrm{D}$ or $6 \mathrm{~L}: 18 \mathrm{D}$. Treatments continued for a further 56 days. Increase in the activity of the hypothalamo-hypophysial system occurred within 4 days of exposure to $16 \mathrm{~L}: 8 \mathrm{D}$, as shown by significant elevation of plasma LH and FSH. Pituitary LH did not increase until Day 7, and pituitary FSH did not increase until Day 21. After exposure to 16L:8D for 4 days, pituitary FSH was lower than in corresponding animals in 6L:18D. These discrepancies between pituitary and plasma values of gonadotrophins indicate that increase in hormone release occurs before synthesis is fully stimulated. Enhanced output of testicular hormones probably began between Day 7 and Day 14, as indicated by an increase in seminal vesicle weight, yet plasma and pituitary concentrations of LH and FSH remained elevated. This suggests that long photoperiods may cause direct stimulation of the hypothalamo-hypophysial system which increasing values of testicular hormones are initially unable to inhibit. The response of this system in voles to an abrupt change from a non-stimulating to a stimulating photoperiod has a time course resembling that for the Soay ram but appreciably slower than for the Japanese quail.
\end{abstract}

\section{Introduction}

The annual cycle of reproduction of the vole (Microtus agrestis) involves a breeding season which generally lasts from March until the end of September, and a non-breeding period from October to March (Baker \& Ranson, 1933). In the non-breeding period two types of animal can be recognized: voles that were sexually mature in the preceding breeding season, and voles born late in the previous breeding season and which, because of the unfavourable environmental conditions of the autumn, do not become sexually active in the year of their birth (Clarke \& Forsyth, 1964). The main environmental factor determining the reproductive state of voles is daylength (Baker \& Ranson, 1932, 1933; Clarke \& Kennedy, 1967; Grocock \& Clarke, 1974). Rearing laboratory bred voles from birth in short ( $6 \mathrm{~h}$ light:18 h dark; 6L:18D) or long (16L:8D) photoperiods can be used to give some idea of the state of the hypothalamo-hypophysial-gonadal system in animals in which sexual development is inhibited by the onset of autumn soon after their birth, and in others that mature sexually after their birth in spring (Craven \& Clarke, 1982). It is obvious that, after the change from a non-stimulating to stimulating photoperiod, complete sexual maturation of a seasonally breeding mammal such as the vole, with the formation of spermatozoa and ovulable follicles, will take a number of weeks, since growth and differentiation of gonadal tissues and cells must occur (Pedersen, 1970; Grocock \& Clarke, 1975). Alteration in the activity of the anterior 
pituitary in such circumstances is likely to be very much more rapid. The speed of this response could serve to define characteristics of the neuroendocrine systems responsible for the reaction to photoperiod.

The system in the Japanese quail, reacting to a first long photoperiod within the first $24 \mathrm{~h}$ of its onset, is presumably organized in a different way from that of the Soay ram, in which the response to sustained stimulating photoperiods occurs some days after they have begun (Follett, Davies \& Gledhill, 1977; Lincoln \& Peet, 1977). A preliminary study showed that quite large increases in uterine, ovarian and pituitary weight occur in voles within 2 weeks of a shift from $6 \mathrm{~L}: 18 \mathrm{D}$ to 16L:8D (Clarke, 1972). Here we report the change in gonadotrophin secretion and in the size of testes and seminal vesicles of voles exposed to $6 \mathrm{~L}: 18 \mathrm{D}$ for the first month after birth, and then transferred for up to a further 2 months to $16 \mathrm{~L}: 8 \mathrm{D}$. Such alterations can be taken to represent at least some of the aspects of the transformation of overwintered 'inhibited' animals as they experience their first spring.

\section{Materials and Methods}

Voles were from the colony maintained in the Department of Agricultural Science, Oxford. They were fed and housed as described by Grocock \& Clarke (1974). Pregnant females were transferred from the Animal House, where the photoperiod is $16 \mathrm{~h}$ light:8 h dark (16L:8D) to light-proof cabinets in which the lighting regimen was $6 \mathrm{~L}: 18 \mathrm{D}$. The young born to these females were reared in the short photoperiod through weaning (at 16 days) to the age of 28 days. Pairs of males, matched for body weight and the lack of sexual development (as judged by a juvenile penis and the absence of any sign of a scrotum), were assigned at random to $16 \mathrm{~L}: 8 \mathrm{D}$ or $6 \mathrm{~L}: 18 \mathrm{D}$. After $2,4,7,14,21,28$, 35,42 or 56 days such pairs were anaesthetized with ether and a terminal blood sample was withdrawn into heparinized syringes. Blood samples were taken between 11:00 and 12:00 h. The blood was centrifuged and the plasma stored at $-20^{\circ} \mathrm{C}$ until assayed. Pituitary glands (including the posterior lobe) were removed immediately after death, weighed and stored at $-20^{\circ} \mathrm{C}$ until assayed. Carcases were fixed in $10 \%$ formalin, and paired testes and seminal vesicles were later weighed. Pituitaries were homogenized in phosphate-buffered saline, $\mathrm{pH}$ 7.0.

Dilutions of plasma from castrated voles and vole pituitary homogenates react with anti-ovine LH and anti-rat FSH to produce dilution curves parallel to those for ovine and rat standards (Craven \& Clarke, 1982). Plasma and pituitary gonadotrophins were assayed using a heterologous double-antibody radioimmunoassay, using the ultra-microassay described by Naftolin \& Corker (1971). The lowest detectable levels were $0.1 \mathrm{ng} \mathrm{LH} / \mathrm{ml}$ and $10 \cdot 8 \mathrm{ng} \mathrm{FSH} / \mathrm{ml}$. Samples from a single pool of plasma from castrated voles were assayed and used to calculate inter- and intra-assay coefficients of variation which were, respectively, $8.4 \%$ and $6.7 \%$ for $\mathrm{LH}$ and $5.4 \%$ and $8.1 \%$ for FSH.

Data were analysed by analysis of variance and the $t$ test for the significance of differences between means. Values of $P<0.05$ have been regarded as indicating statistical significance.

\section{Results}

\section{Organ weights}

Analyses of variance showed that the pituitaries, testes and seminal vesicles increased in weight significantly over the 56 days of each treatment (Fig. 1). However, the increase in weight of these organs was in absolute and relative terms very much greater in the voles exposed to $16 \mathrm{~L}: 8 \mathrm{D}$ than in those exposed to $6 \mathrm{~L}: 18 \mathrm{D}$. Testes were significantly larger after 7 days, and pituitaries and seminal vesicles after 14 days, in the animals exposed to $16 \mathrm{~L}: 8 \mathrm{D}$, and significant differences in organ 

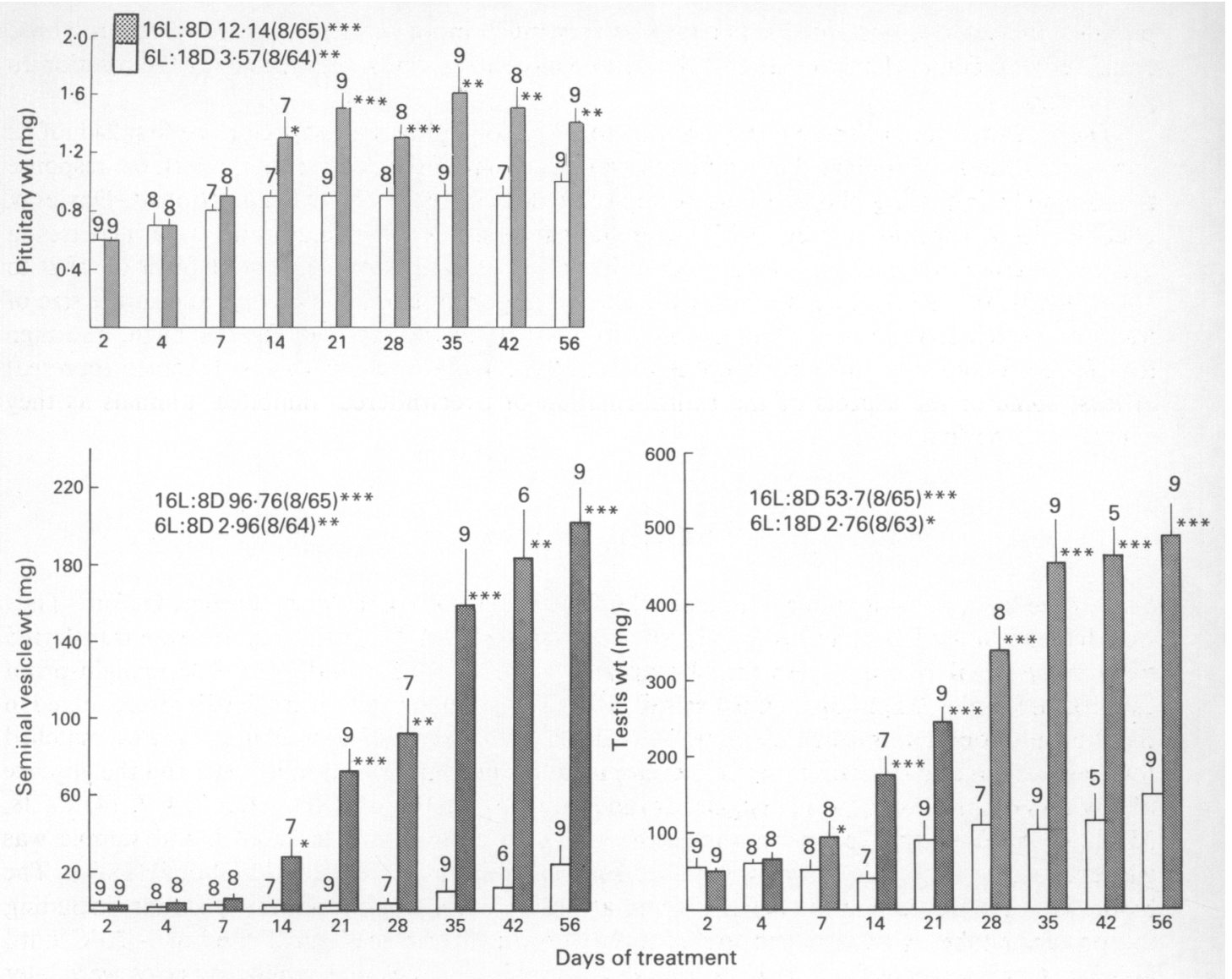

Fig. 1. Weights of pituitaries, testes and seminal vesicles from male voles exposed to $16 \mathrm{~L}: 8 \mathrm{D}$ or $6 \mathrm{~L}: 18 \mathrm{D}$. Values are means \pm s.e.m. for the sample sizes indicated. $\mathrm{F}$ ratios from analysis of variance, and degrees of freedom are also given. ${ }^{*} P<0.05 ;{ }^{* *} P<0.01 ;{ }^{* * *} P<0.001$.

weights were maintained thereafter. The onset of marked growth in pituitary, testis and seminal vesicle weight occurred between Days 7 and 14 of exposure to $16 \mathrm{~L}: 8 \mathrm{D}$. In $6 \mathrm{~L}: 18 \mathrm{D}$ the onset of testicular enlargement began between 21 and 28 days from the start of the contrasting treatments (exposure to $6 \mathrm{~L}: 18 \mathrm{D}$ for $49-56$ days from birth), and between 28 and 35 days (56-63 days from birth) for seminal vesicles (Fig. 1).

\section{Plasma and pituitary gonadotrophin concentrations}

Analysis of variance showed that there were significant changes in plasma LH values over the 56 days of treatment in voles in 16L:8D and 6L:18D. On Days 4, 7, 21, 35 and 42 after transfer to $16 \mathrm{~L}: 8 \mathrm{D}$, plasma concentrations were significantly higher than in corresponding voles from $6 \mathrm{~L}: 18 \mathrm{D}$ (Fig. 2). Pituitary LH values also changed significantly with time in voles exposed to $16 \mathrm{~L}: 8 \mathrm{D}$, but not in those that remained in $6 \mathrm{~L}: 18 \mathrm{D}$ (Fig. 2). Pituitary $\mathrm{LH}$ values were significantly higher in voles transferred to $16 \mathrm{~L}: 8 \mathrm{D}$ than in corresponding animals remaining in $6 \mathrm{~L}: 18 \mathrm{D}$ at Day 7 of exposure to 16L:8D and thereafter until and including Day 42. 

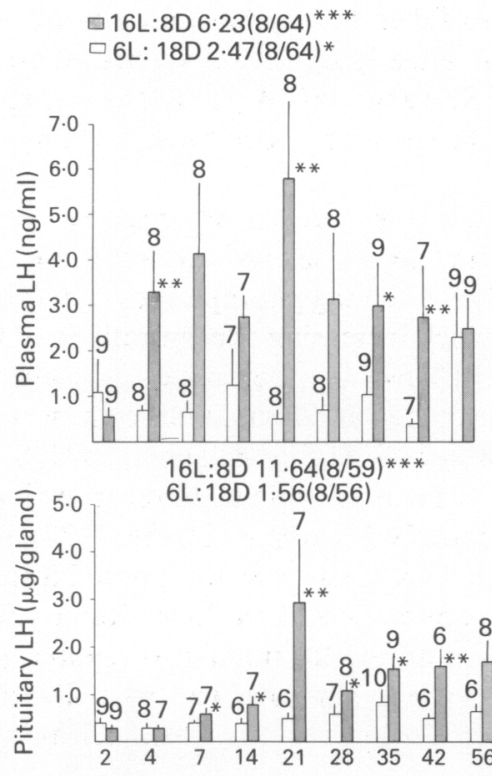
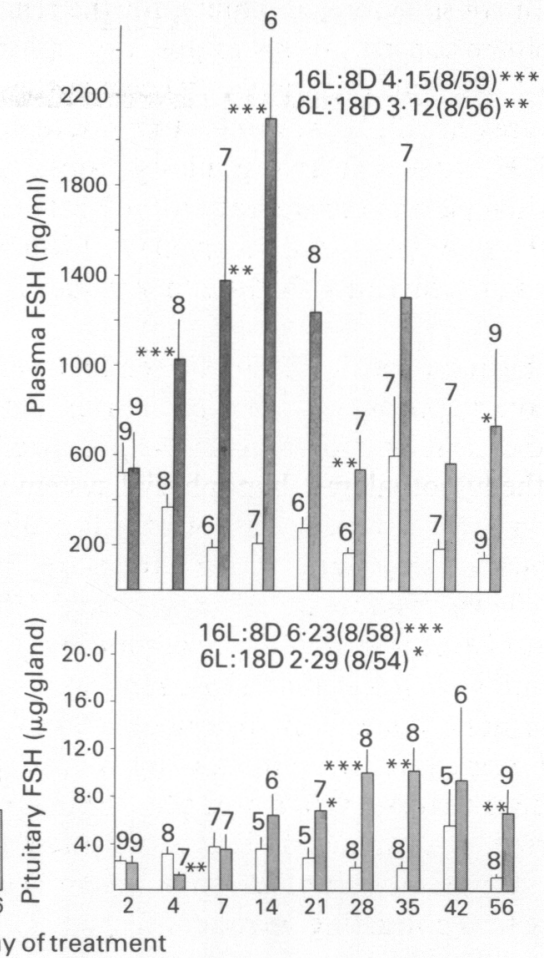

Fig. 2. Plasma and pituitary concentrations of LH and FSH in male voles exposed to $16 \mathrm{~L}: 8 \mathrm{D}$ or $6 \mathrm{~L}: 18 \mathrm{D}$. Values are means \pm s.e.m. for the sample sizes indicated. $\mathrm{F}$ ratios from analysis of variance, and degrees of freedom are also given. ${ }^{*} P<0.05 ;{ }^{* *} P<0.01$; ${ }^{* * *} P<0.001$.

There was a significant overall effect of duration of treatment (whether long, or continuing short, photoperiod) upon plasma concentrations of FSH (Fig. 2). From Day 4 until Day 28 after transfer to 16L:8D, and again at Day 56, plasma FSH values were higher than in corresponding animals from 6L:18D, reaching peak value at Day 14 after transfer (Fig. 2). Analysis of variance also showed that pituitary FSH changed significantly with time in both photoperiods (Fig. 2). By Day 4 of exposure to $16 \mathrm{~L}: 8 \mathrm{D}$, pituitary FSH values had dropped to a value significantly lower than that for voles continuing in $6 \mathrm{~L}: 18 \mathrm{D}$. By 7 days, the concentrations of FSH in the pituitary were the same in animals in both photoperiods, and thereafter significantly higher (except on Day 42) in voles exposed to $16 \mathrm{~L}: 8 \mathrm{D}$ than in those remaining in $6 \mathrm{~L}: 18 \mathrm{D}$ (Fig. 2).

\section{Discussion}

As judged by the concentrations of FSH and LH, an increase in the activity of the hypothalamo-hypophysial system of the 'inhibited' vole occurs within 4 days of exposure to a long photoperiod. The time course for these changes is appreciably slower than the equivalent response reported for the Japanese quail, but similar to that for golden and Djungarian hamsters, and Soay rams (Berndtson \& Desjardins, 1974; Follett et al., 1977; Lincoln \& Peet, 1977; Simpson, Follett \& Ellis, 1982). The plasma concentrations of voles in long, compared with short, photoperiods were 
maintained, with considerable variability, for the remainder of the 56-day treatment. A significant increase in pituitary concentrations of gonadotrophins occurred more slowly, by 14 days for LH and 21 days for FSH. This is presumably because the mechanism for release is activated before the synthesis processes are fully working. The discrepancy between synthesis and release is more apparent for FSH, since at Day 4 pituitary values had fallen below those for voles in the short photoperiod, while plasma concentrations of FSH were already significantly elevated above those for animals in the short photoperiod. By Day 21 (for FSH) and Day 14 (for LH), synthesis of each hormone had risen sufficiently for pituitary values to be elevated above those for animals in the short photoperiod.

As judged by increase in weight of seminal vesicles the onset of appreciable secretion of testicular hormones appears to take place during the first 14-21 days of exposure to long photoperiods. It can therefore be concluded that exposure of voles to long photoperiods results in a direct stimulation of the hypothalamo-hypophysial system which increasing concentrations of testicular hormones are initially unable to inhibit. Such a direct effect of photoperiod has already been suggested for the snowshoe hare, the ram, the mare, the golden and Djungarian hamsters (Davis $\&$ Meyer, 1973; Pelletier \& Ortavant, 1975; Garcia \& Ginther, 1976; Ellis \& Turek, 1980; Simpson $e t$ al., 1982; Urbanski \& Simpson, 1982, 1983). Pituitary FSH concentrations in voles remaining in the short photoperiod were lower than those reported previously (Craven \& Clarke, 1982), but in the earlier study hormone values were measured at 14 to 56 days of age in voles exposed from birth to long or short photoperiods. In animals living in the short photoperiod, the high pituitary content of FSH up to 35 days suggested that storage of FSH occurs during the initial post-natal exposure to short photoperiod. It seems likely that in the present experiment voles had passed through this storage phase during the initial 28 days in the short photoperiod to which all animals were subjected before the contrasting treatments began.

Changes in organ weights occur almost as rapidly as the alterations in synthesis and release of gonadotrophins. Significant increases in testicular weight had occurred after 7 days, and in pituitaries and seminal vesicles after 14 days exposure to the long photoperiod. Over comparable periods after first exposure to 16L:8D, whether from birth (Craven \& Clarke, 1982) or from 28 days of age in the present study, rates of growth of the testes, seminal vesicles and pituitary gland are essentially the same. However, in the present study these organs were appreciably larger. At the start of treatments males transferred to the long photoperiod from the short were 28 days old, and despite being reared in $6 \mathrm{~L}: 18 \mathrm{D}$ up to that age, testes and seminal vesicles had grown from weights at birth of $2.7 \pm 0.2$ and $0.12 \pm 0.02 \mathrm{mg}$ respectively, to $4.0 \pm 4.0$ and $1.7 \pm 0.16 \mathrm{mg}$ (Grocock, 1972, 1979; Craven \& Clarke, 1982).

Examination of changes in synthesis and release of LH and FSH in the present results and in voles exposed from birth to long or short photoperiods (Craven \& Clarke, 1982) suggests that the response to long photoperiod applied from birth is different from that of animals reared from birth to 28 days in short photoperiod and then transferred to long photoperiod. Pituitary concentrations of $\mathrm{LH}$ had increased significantly after 14 days in animals transferred to $16 \mathrm{~L}: 8 \mathrm{D}$, while there was no significant increase in pituitary LH until 35 days in those born in a long photoperiod (Craven \& Clarke, 1982). Likewise, the alterations in FSH synthesis and release after the start of 16L:8D do not occur at corresponding times in transferred voles and those born and reared in the long photoperiod. Horton $(1984 \mathrm{a}, \mathrm{b})$ has shown that the photoperiod occurring before weaning and even during pregnancy influences the post-weaning or post-natal development of montane voles (Microtus montanus). If montane voles are exposed to $8 \mathrm{~L}: 16 \mathrm{D}$ before weaning, or if pregnant females experience this photoperiod during gestation, the sexual development of weaned or of newborn voles in $14 \mathrm{~L}: 10 \mathrm{D}$ is greater than those exposed to $16 \mathrm{~L}: 8 \mathrm{D}$ before weaning, or born from females given such a photoperiod during gestation, and then placed in 14L:10D. However, unlike the suggestion from the present results, sexual development of montane voles at the age of 74 days is the same whether they have been exposed to $8 \mathrm{~L}: 16 \mathrm{D}$ or $16 \mathrm{~L}: 8 \mathrm{D}$ up to the age of 18 days, and thereafter to $16 \mathrm{~L}: 8 \mathrm{D}$. 
We thank Dr G. Fink, Mr R. Laynes and Dr P. C. B. MacKinnon for help with this investigation; Professor G. D. Niswender, Professor L. E. Reichert and the NIAMDD, for the supply of hormones and antibodies; and the Smith Kline Foundation and the Royal Society for grants covering part of the cost of materials and equipment. The investigation was carried out under a grant to J.R.C. from the Medical Research Council (G974/297/B).

\section{References}

Baker, J.R. \& Ranson, R.M. (1932) Factors affecting the breeding of the field mouse (Microtus agrestis). Part I. Light. Proc. R. Soc. B 110, 313-322.

Baker, J.R. \& Ranson, R.M. (1933) Factors affecting the breeding of the field mouse (Microtus agrestis). Part III. Locality. Proc. R. Soc. B 113, 486-495.

Berndtson, W.E. \& Desjardins, C. (1974) Circulating LH and FSH levels and testicular function in hamsters during light deprivation and subsequent photoperiodic stimulation. Endocrinology 95, 195-205.

Clarke, J.R. (1972) Seasonal breeding in female mammals. Mam. Rev. 1, 217-230.

Clarke, J.R. \& Forsyth, I.A. (1964) Seasonal changes in the gonads and accessory reproductive organs of the vole (Microtus agrestis). Gen. comp. Endocr. 4, 233-243.

Clarke, J.R. \& Kennedy, J.P. (1967) Effect of light and temperature upon gonad activity in the vole (Microtus agrestis). Gen. comp. Endocr. 8, 474 478.

Craven, R.P. \& Clarke, J.R. (1982) Gonadotrophin levels in male voles (Microtus agrestis) reared in long and short photoperiods. J. Reprod. Fert. 66, 709-714.

Davis, G.J. \& Meyer, R.K. (1973) Seasonal variation in LH and FSH of bilaterally castrate snowshoe hares. Gen. comp. Endocr. 20, 61-68.

Ellis, G.B. \& Turek, F.W. (1980) Photoperiodic regulation of serum luteinizing hormone and follicle stimulating hormone in castrated and castratedadrenalectomized male hamsters. Endocrinology 106, 1338-1344.

Follett, B.K., Davies, D.T. \& Gledhill, B. (1977) Photoperiodic control of reproduction in the Japanese quail: changes in gonadotrophin secretion on the first day and their pharmacological blockade. J. Endocr. 74, 449-460.

Garcia, M.C. \& Ginther, O.J. (1976) Effects of ovariectomy and season on plasma luteinizing hormone in mares. Endocrinology 98, 958-962.

Grocock, C.A. (1972) The influence of some environmental factors on the testis of the vole with particular reference to spermatogenesis. D. Phil. thesis, Oxford University.

Grocock, C.A. (1979) Testis development in the vole, Microtus agrestis, subjected to long or short photoperiods from birth. J. Reprod. Fert. 55, $423-427$.
Grocock, C.A. \& Clarke, J.R. (1974) Photoperiodic control of testis activity in the vole, Microtus agrestis. J. Reprod. Fert. 39, 337-347.

Grocock, C.A. \& Clarke, J.R. (1975) Spermatogenesis in mature and regressed testes of the vole (Microtus agrestis). J. Reprod. Fert. 43, 461-470.

Horton, T.H. (1984a) Growth and maturation in Microtus montanus; modifications by photoperiods before and after weaning. Can. J. Zool. 62, 1741-1746.

Horton, T.H. (1984b) Growth and reproductive development of male Microtus montanus is affected by the prenatal photoperiod. Biol. Reprod. 31, 499-504.

Lincoln, G.A. \& Peet, M.J. (1977) Photoperiodic control of gonadotrophin secretion in the ram; a detailed study of the temporal changes in plasma levels of follicle stimulating hormone, luteinising hormone and testosterone following an abrupt switch from long to short days. J. Endocr. 74, 355-367.

Naftolin, F. \& Corker, C.S. (1971) An ultramicro method for the measurement of luteinising hormone by radioimmunoassay. In Radioimmunoassay Methods, pp. 641-650. Eds K. E. Kirkham \& W. H. Hunter. Churchill, London.

Pedersen, T. (1970) Determination of follicle growth rate on the ovary of the immature mouse. J. Reprod. Fert. 21, 8I-93.

Pelletier, J. \& Ortavant, R. (1975) Photoperiodic control of $\mathrm{LH}$ release in the ram. 1. Influence of increasing and decreasing day-length. Acta endocr., Copenh. 78, 435-44I.

Simpson, S.M., Follett, B.K. \& Ellis, D.H. (1982) The modulation by photoperiod of gonadotrophin secretion in intact and castrated Djungarian hamsters. J. Reprod. Fert. 66, 243-250.

Urbanski, H.F. \& Simpson, S.M. (1982) Photoperiodic suppression of gonadotrophin secretion in castrated male hamsters. J. Reprod. Fert. 66, 299-303.

Urbanski, H.F. \& Simpson, S.M. (1983) Effects of short-term treatment with testosterone on the secretion of FSH and LH in castrated golden hamsters exposed to short days. J. Reprod. Fert. 69, 489 496.

Received 8 March 1985 